This document is confidential and is proprietary to the American Chemical Society and its authors. Do not copy or disclose without written permission. If you have received this item in error, notify the sender and delete all copies.

\title{
Alternating Copolymerization of Propylene Oxide and Cyclohexene Oxide with Tricyclic Anhydrides: Access to Partially Renewable Aliphatic Polyesters with High Glass Transition Temperatures
}

\begin{tabular}{|r|l|}
\hline Journal: & Macromolecules \\
\hline Manuscript ID & ma-2016-014256.R1 \\
\hline Manuscript Type: & Article \\
\hline Date Submitted by the Author: & 03-Aug-2016 \\
\hline Complete List of Authors: & $\begin{array}{l}\text { Sanford, Maria; Cornell University, Chemistry and Chemical Biology } \\
\text { Leticia Peña Carrodeguas, Leticia; Institute of Chemical Research of } \\
\text { Catalonia (ICIQ), } \\
\text { Van Zee, Nathan; Cornell University, } \\
\text { Kleij, Arjan; Institute of Chemical Research of Catalonia (ICIQ), Research } \\
\text { group Kleij } \\
\text { Coates, Geoffrey; Cornell University, Chemistry and Chemical Biology; } \\
\text { Cornell University, Chemistry and Chemical Biology }\end{array}$ \\
\hline
\end{tabular}

\section{SCHOLARONE"}

Manuscripts

"This document is the Accepted Manuscript version of a Published Work that appeared in final form ir Macromolecules 2016, 49, 6394-6400, copyright (c) American Chemical Society after peer review and technica editing by the publisher. To access the final edited and published work see DOI: 10.1021/acs.macromol.6b01425. This article may be used for non-commercial purposes in accordance with the ACS guidelines published at http://pubs.acs.org/page/policy/articlesonrequest/index.html]." 


\title{
Alternating Copolymerization of Propylene Oxide and Cyclohexene Oxide with Tricyclic Anhydrides:
}

\section{Access to Partially Renewable Aliphatic Polyesters}

\section{with High Glass Transition Temperatures}

\author{
Maria J. Sanford,$^{\ddagger}$ Leticia Peña Carrodeguas,${ }^{\S}$ Nathan J. Van Zee,${ }^{\dagger, *}$ Arjan W. Kleij, ${ }^{*, \S}$ and \\ Geoffrey W. Coates*,
}

${ }^{\ddagger}$ Department of Chemistry and Chemical Biology, Baker Laboratory, Cornell University, Ithaca, NY 14853-1301, USA

${ }^{\S}$ Institute of Chemical Research of Catalonia (ICIQ), Av. Països Catalans 16, 43007 Tarragona, Spain

\begin{abstract}
Renewable, biodegradable polymers, such as aliphatic polyesters, based on sustainable sources have attracted considerable interest as alternatives to petroleum based polymers. One limiting factor in the development of aliphatic polyesters as replacements for these materials has been their relatively low glass transition temperatures $\left(T_{\mathrm{g}}\right)$. For example, commercially available poly(lactic acid) has a $T_{\mathrm{g}}$ of approximately $60{ }^{\circ} \mathrm{C}$. Epoxide/anhydride copolymerizations offer an alternative to the ring-opening polymerization of lactones for the synthesis of aliphatic polyesters, and allow for tuning of polymer properties through two distinct
\end{abstract}


monomer sets. We synthesized six partially or fully renewable tricyclic anhydrides and copolymerized them with propylene oxide (PO) and cyclohexene oxide (CHO). By varying both the epoxide and the anhydride we were able to tune the $T_{\mathrm{g}}$ of the resulting polymers over a nearly $120{ }^{\circ} \mathrm{C}$ range from $66^{\circ} \mathrm{C}$ to an exceptionally high $184{ }^{\circ} \mathrm{C}$. Polymers produced with $\mathrm{PO}$ had a lower range of $T_{\mathrm{g}}$ values $\left(66-108^{\circ} \mathrm{C}\right)$ and higher molecular weights up to $32.2 \mathrm{kDa}$, while those produced with $\mathrm{CHO}$ had higher $T_{\mathrm{g}}$ values $\left(124-184^{\circ} \mathrm{C}\right)$ and lower molecular weights, showing the profound influence of both monomer sets. To the best of our knowledge, these are the highest $T_{\mathrm{g}}$ values reported for entirely aliphatic polyesters.

As society has become more dependent on plastics, the sustainability of these materials has become an increasingly important issue. Polymers that are produced from sustainable feedstocks such as biomass and those that are biodegradable have attracted considerable interest as alternatives to fossil fuel-based polymers. ${ }^{1}$ In particular, aliphatic polyesters are appealing because of their numerous renewable sources, ${ }^{1 \mathrm{~b}, 1 \mathrm{~d}, 2}$ facile hydrolytic degradation to benign products, ${ }^{2 b, 3}$ and general biocompatibility. ${ }^{4}$ These features have led to aliphatic polyesters being utilized in applications ranging from specialized biomedical devices to bulk packaging., ${ }^{4,5}$

The most common route to produce aliphatic polyesters is the ring-opening polymerization (ROP) of lactones and lactide. ${ }^{6}$ Numerous initiators have been used for lactone polymerization, including organocatalysts, metal alkoxides, and various metal complexes. ${ }^{4}$ However, the ROP of lactones can be limited by detrimental side reactions such as transesterification, especially at high conversion. The resulting polymers also have a limited range of properties, because of the limited functional diversity of the substrate scope and lack of post-polymerization 
functionalization on the resulting polyesters. ${ }^{4,6}$ There has been interest in developing higher $T_{\mathrm{g}}$ aliphatic polyesters, since commercially available poly(lactic acid) (PLA) has a relatively low $T_{\mathrm{g}}$ (approximately $60^{\circ} \mathrm{C}$ ). Efforts to improve the $T_{\mathrm{g}}$ of aliphatic polyesters have mainly focused on using polysaccharide derived diols, ${ }^{7}$ and lactide ${ }^{8}$ or $_{\text {mannitol }}^{9}$ derivatives. However, the resulting polymers either show modest improvements over PLA $\left(T_{\mathrm{g}}\right.$ up to $\left.68{ }^{\circ} \mathrm{C}\right){ }^{7 \mathrm{a}, 9}$ or require long reaction times at low temperatures $\left(-20{ }^{\circ} \mathrm{C}\right)$ to reach moderate conversion. ${ }^{8}$ An alternative synthetic route to aliphatic polyesters is the alternating copolymerization of epoxides and cyclic anhydrides (Scheme 1). ${ }^{6}$ The use of two monomers allows for more facile tuning of properties, and many of the resulting polyesters can be easily functionalized by post-polymerization modification. ${ }^{6,10}$ There is a diverse array of metal complexes reported to catalyze the copolymerization, including zinc, ${ }^{11}$ magnesium, ${ }^{11 \mathrm{~d}, 11 \mathrm{f}, 12}$ chromium, ${ }^{11 \mathrm{f}, 13}$ cobalt, ${ }^{11 \mathrm{f}, 13 \mathrm{~b}, 13 \mathrm{~d}-\mathrm{f}, 13 \mathrm{i}, 14}$ manganese, ${ }^{13 \mathrm{~b}, 13 \mathrm{i}, 15}$ and aluminum ${ }^{13 \mathrm{~b}, 13 \mathrm{e}, 13 \mathrm{f}, 13 \mathrm{i}, 16}$ complexes, including a wide range of salen- and porphyrin-type complexes which generally show markedly improved activity with the addition of a nucleophilic co-catalyst such as bis(triphenylphosphine)iminium chloride $\left(\left[\mathrm{Ph}_{3} \mathrm{P}-\mathrm{N}=\mathrm{PPh}_{3}\right] \mathrm{Cl}\right.$ or $[\mathrm{PPN}] \mathrm{Cl})$.

Scheme 1. Alternating copolymerization of epoxides and cyclic anhydrides, and simplified proposed reaction mechanism.

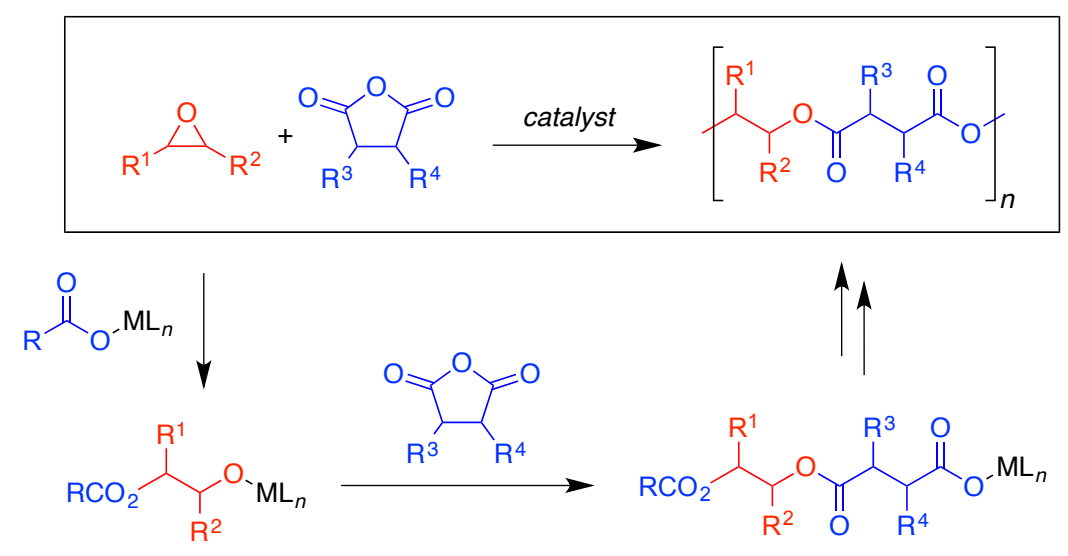


The Coates group has recently focused on the alternating copolymerization of epoxides and tricyclic anhydrides with aluminum salen complexes. ${ }^{16 c, 16 \mathrm{~d}}$ Tricyclic anhydrides are appealing monomers that are easily synthesized via the Diels-Alder reaction. The wide range of commercially available, inexpensive, biosourced dienes and dienophiles offers ample opportunities for utilizing renewable feedstocks. Additionally, the rigid nature of the resulting polymers yields materials with high glass transition temperatures $\left(T_{\mathrm{g}}\right)$. Recently, we reported the chain-growth copolymerization of propylene oxide and a terpene based tricyclic anhydride, which yielded a completely amorphous aliphatic polyester with a $T_{\mathrm{g}}$ of $109{ }^{\circ} \mathrm{C} .{ }^{16 \mathrm{c}}$ Additionally, transesterification and epimerization could be suppressed even at high conversion through judicious choice of catalyst, the ratio of catalyst to cocatalyst, and the steric requirements of the monomers. ${ }^{16 c, 16 \mathrm{~d}}$ In addition to screening these (salen)AlCl catalysts for a wider range of monomers, we were also interested in exploring a geometrically more flexible ${ }^{17}$ iron aminotriphenolate complex because it has been shown to be active for copolymerization of epoxides and $\mathrm{CO}_{2}{ }^{18}$ and iron complexes have previously been used in epoxide/anhydride copolymerizations. Recently, Merna and coworkers reported the use of (salen)FeCl complexes for the copolymerization of cyclohexene oxide and phthalic anhydride, ${ }^{19}$ and Nozaki reported using an iron corrole complex for the alternating copolymerization of propylene oxide and glutaric anhydride. ${ }^{15 a}$ In general, iron complexes are of interest due to the high natural abundance of iron and its low toxicity. Because of the potential uses of aliphatic polyesters in biomedical applications, metal catalysts with low toxicity are of interest because of residual catalyst trapped in the polymer. Herein, we report an expansion of our previous work to six anhydrides and two epoxides to synthesize twelve partially renewable aliphatic polyesters with $T_{\mathrm{g}}$ values that are tunable from $66^{\circ} \mathrm{C}$ to $184{ }^{\circ} \mathrm{C}$. 
Scheme 2. Synthesis of renewable precursors for tricyclic anhydrides.

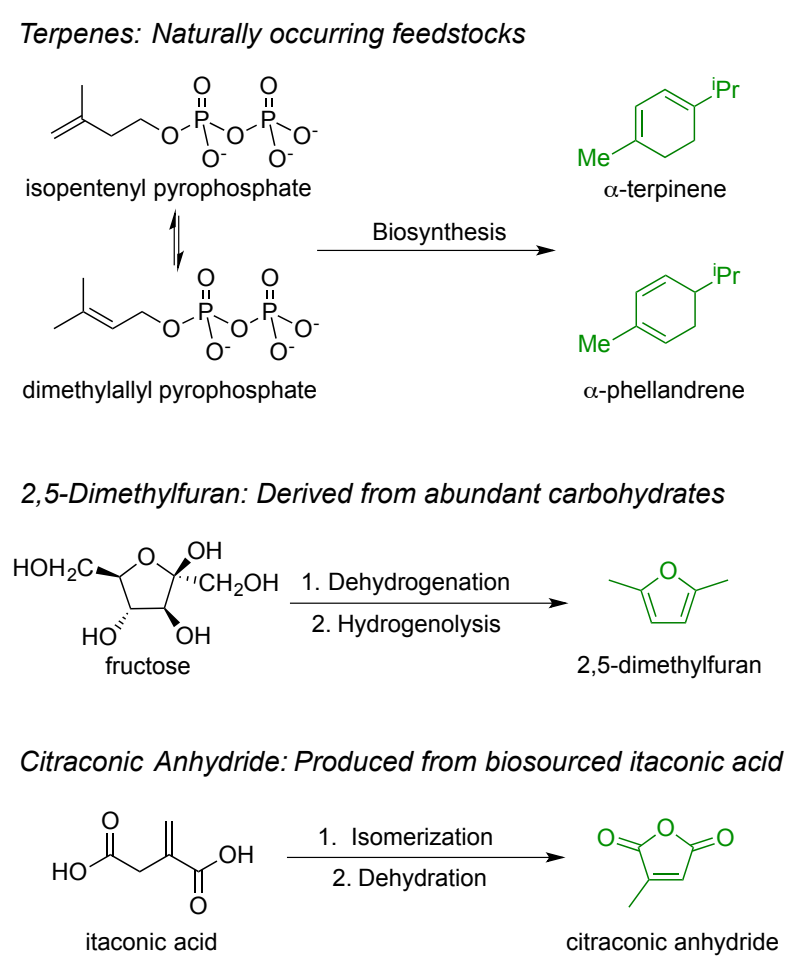

On the basis of our previous work, ${ }^{16 c, 16 \mathrm{~d}}$ and the range of renewable dienes and dienophiles available, we chose to focus on tricyclic anhydrides due to their well-controlled polymerization behavior and typically higher $T_{\mathrm{g}}$ values due to rigidity of the anhydride unit. We synthesized six partially or fully renewable anhydrides based on $\alpha$-terpinene, $\alpha$-phellandrene, citraconic anhydride, and 2,5-dimethylfuran. Terpenes such as $\alpha$-terpinene and $\alpha$-phellandrene (Scheme 2) are part of a class of naturally occurring molecules synthesized through biosynthetic pathways, that have been extensively investigated as renewable building blocks. ${ }^{20}$ Dehydration and subsequent hydrogenolysis of carbohydrates leads to 2,5-dimethylfuran (Scheme 2) that has been investigated as a potential renewable liquid fuel. ${ }^{21}$ Citraconic anhydride (Scheme 2) is produced from the isomerization and dehydration of itaconic acid. ${ }^{22}$ This naturally occurring acid, which is 
commonly produced industrially by fermentation of carbohydrates, ${ }^{23}$ is one of the U.S. Department of Energy's top twelve value added chemicals derived from biomass. ${ }^{24}$

Scheme 3. Synthesis of partially renewable tricyclic anhydrides from a) terpenes, b) citraconic anhydride, c) 2,5-dimethylfuran, and d) completely renewable tricyclic anhydrides.

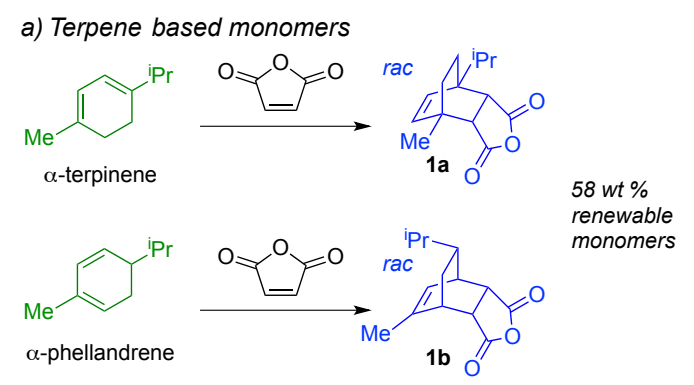

b) Citraconic anhydride based monomers

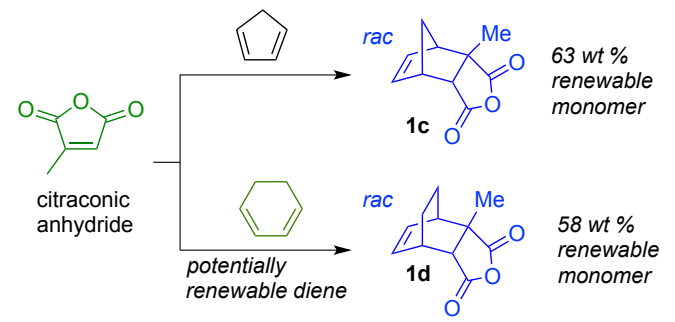

c) 2,5-Dimethylfuran based monomer

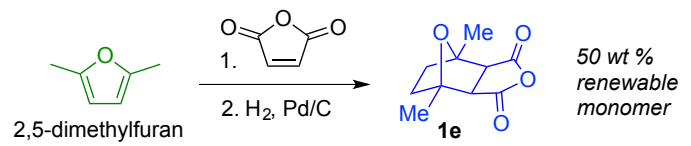

d) Citraconic anhydride and $\alpha$-phellandrene based monomers

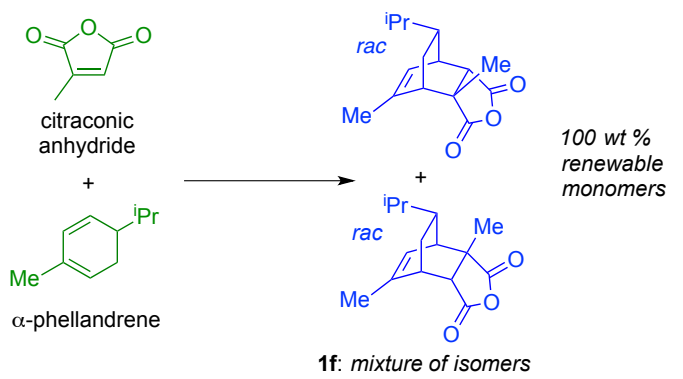

We used the renewable precursors in Scheme 2 to synthesize five tricyclic anhydrides (1a-1e) through Diels-Alder reactions, creating a series of anhydrides that are 50-63\% renewable by mass (Scheme 3a-c). Monomer 1d has the potential to be completely renewable, as 1,3- 
cyclohexadiene has been synthesized though the metathesis of plant oils. ${ }^{25}$ The Diels-Alder adduct of maleic anhydride and 2,5-dimethylfuran undergoes a rapid retro Diels-Alder reaction in the presence of Lewis acidic catalysts, so it was saturated via catalytic hydrogenation to access an anhydride stable enough for polymerization. We also synthesized a completely renewable anhydride through the Diels-Alder reaction of citraconic anhydride and $\alpha$-phellandrene. This reaction yielded an inseparable mixture of structural isomers in a 54:46 ratio (1f, Scheme 3d). This mixture of isomers may aid in achieving the desired rigid, completely amorphous polymer backbone. Other Diels-Alder reactions between combinations of renewable dienes and dieneophiles that would have yielded completely renewable anhydrides (e.g. citraconic anhydride and $\alpha$-terpinene or 2,5-dimethylfuran) were not successful under routine conditions, likely due to steric bulk hindering the reaction. 
Table 1. Copolymerization of $\mathbf{1 a}-\mathbf{1 f}$ with propylene oxide (PO).
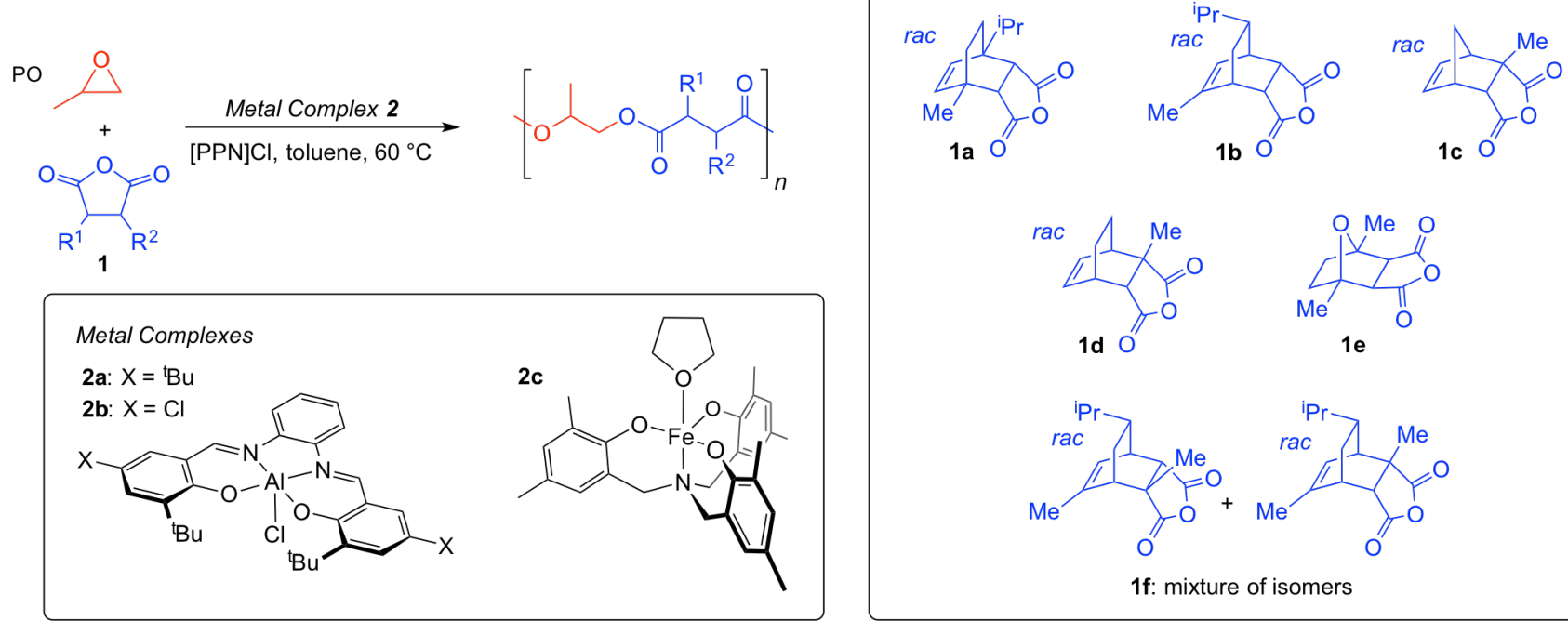

2a: $X=\mathrm{Bu}$
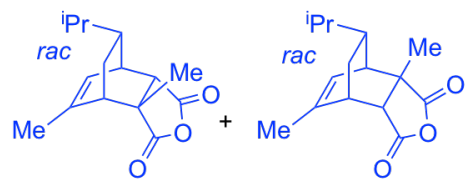

1f: mixture of isomers

\begin{tabular}{|c|c|c|c|c|c|c|c|c|}
\hline Entry & Anhyd. & Complex & $\begin{array}{l}t_{\mathrm{rxn}} \\
\text { (h) }\end{array}$ & $\begin{array}{c}\text { Conv. } \\
(\%)^{b}\end{array}$ & $\begin{array}{c}M_{\mathrm{n}} \\
(\mathbf{k D a})^{c}\end{array}$ & $\bigoplus^{c}$ & $T_{\mathbf{g}}\left({ }^{\circ} \mathbf{C}\right)^{d}$ & $\% c i s^{\mathrm{e}}$ \\
\hline 1 & $1 a$ & $2 \mathbf{a}$ & 5 & $>99$ & 29.2 & 1.10 & 108 & $>99$ \\
\hline 2 & $1 a$ & $2 c$ & 6 & $>99$ & 15.3 & 1.13 & 103 & $>99$ \\
\hline 3 & $1 b$ & $2 \mathrm{~b}$ & 10 & $>99$ & 30.0 & 1.12 & 91 & $>99$ \\
\hline 4 & $1 \mathrm{~b}$ & $2 c$ & 6 & $>99$ & 17.2 & 1.10 & 91 & $>99$ \\
\hline 5 & $1 c$ & $2 a$ & 3.5 & $>99$ & 32.2 & 1.07 & 79 & $>99$ \\
\hline 6 & 1c & $2 c$ & 6 & $>99$ & 11.1 & 1.14 & 74 & $>99$ \\
\hline 7 & 1d & $2 a$ & 4 & $>99$ & 28.1 & 1.12 & 86 & $>99$ \\
\hline 8 & 1d & $2 c$ & 8 & $>99$ & 10.5 & 1.11 & 66 & $>99$ \\
\hline 9 & $1 e$ & $2 \mathrm{~b}$ & 18 & $>99$ & 29.8 & 1.10 & 92 & $>99$ \\
\hline 10 & 1e & $2 c$ & 5.5 & $>99$ & 10.4 & 1.28 & 86 & 36 \\
\hline 11 & 1f & $2 a$ & 3.5 & $>99$ & 18.7 & 1.10 & 100 & $>99$ \\
\hline 12 & 1f & $2 c$ & 7 & $>99$ & 11.3 & 1.11 & 90 & $>99$ \\
\hline
\end{tabular}

${ }^{a}[\mathrm{PO}]:[1]:[2]:[(\mathrm{PPN}) \mathrm{Cl}]=1500: 300: 1: 0.9^{b}$ Conversion of cyclic anhydride, determined by ${ }^{1} \mathrm{H}$ NMR spectroscopy. ${ }^{c}$ Determined by GPC in THF, at $30{ }^{\circ} \mathrm{C}$, calibrated with polystyrene standards. ${ }^{d}$ Determined by DSC; reported $T_{\mathrm{g}}$ values are from the second heat.

${ }^{e}$ Determined by ${ }^{1} \mathrm{H}$ NMR spectroscopy of the mixture of diols obtained from the reductive degradation of the polymer with $\mathrm{LiAlH}_{4}$.

We first polymerized all six anhydrides with propylene oxide (PO). Previous work showed that the copolymerization of $\mathbf{1 a}$ with $\mathrm{PO}$ yielded a polymer with a $T_{\mathrm{g}}$ up to $109{ }^{\circ} \mathrm{C},{ }^{16 \mathrm{c}}$ leading us to believe that we could achieve similarly high $T_{\mathrm{g}}$ values with the other five anhydrides. Excess 
epoxide was used because it is easier to remove from the polymer than solid anhydride and allowed the polymerizations to be run neat, increasing the polymerization rate. Since both catalytic systems had previously shown high selectivity for polyester ${ }^{16 c, d}$ or polycarbonate ${ }^{18}$ formation, we could use excess epoxide without favoring homopolymerization.

With PO, the six anhydrides gave perfectly alternating copolymers with $T_{\mathrm{g}}$ values ranging from 66 to $108{ }^{\circ} \mathrm{C}$ (Table 1 ). The resulting polymers exhibited molecular weights up to $32.2 \mathrm{kDa}$ and $Ð$ values below 1.15 , with the exception of poly(PO-alt-1e) synthesized with $2 \mathbf{c}$ (Table 1, Entry $10)$, which had a broader dispersity $(\bigoplus=1.28)$. Consistent with our previous work, ${ }^{16 \mathrm{~d}}$ we found that an electron-withdrawing complex (2b) was necessary for the less bulky anhydrides $(\mathbf{1 b}, \mathbf{1 e})$ in order to avoid side-reactions at high conversion. Bulkier anhydrides (1a, 1c, 1d, 1f) could be copolymerized using 2a without significant side reactions; these anhydrides required much longer reaction times when using complex $\mathbf{2 b}$. We found that in general $\mathbf{2 c}$ gave lower molecular weights than either $\mathbf{2 a}$ or $\mathbf{2 b}$, and that both systems gave bimodal GPC traces. We propose this could be due to the presence of adventitious water which can react with anhydrides to form diacids, or chain shuttle with a metal alkoxide ultimately forming a diol, both of which can generate new, bifunctional, polymer chains giving rise to a second distribution which is double the molecular weight of $\mathrm{Cl}^{-}$initiated chains. ${ }^{26}$ This increase in the number of chains can depress the overall molecular weight. We found that $\mathbf{2 c}$ was intermediate in rate being slower than $\mathbf{2 a}$ for monomers $\mathbf{1 a}, \mathbf{1 c}, \mathbf{1 d}$, and $\mathbf{1 f}$ and faster than $\mathbf{2 b}$ for monomers $\mathbf{1 b}$ and $\mathbf{1 e . ~ A l l ~ o f ~ t h e ~ p o l y m e r s ~}$ retained a high cis-diester contents $(>99 \%)$ even at full conversion with the exception of poly(PO-alt-1e) synthesized with 2c, which had only 36\% cis-diester linkages at full conversion (Table 1, Entry 10). 
The $T_{\mathrm{g}}$ values ranged from $66^{\circ} \mathrm{C}$ for a low molecular weight sample of poly(PO-alt-1d) (Table 1, Entry 8), to $108^{\circ} \mathrm{C}$ for the higher molecular weight sample of poly(PO-alt-1a) (Table 1, Entry 1). The highest $T_{\mathrm{g}}$ samples were made with the bulkiest anhydrides (1a and 1f) suggesting that increased bulk along the polymer backbone increased the $T_{\mathrm{g}}$ as expected. Poly(PO-alt-1a) and poly(PO-alt-1f) are of particular interest as they have $T_{\mathrm{g}}$ values higher than or comparable to that of widely used polystyrene $\left(T_{\mathrm{g}}=100^{\circ} \mathrm{C}\right)$, respectively. Although there were some differences in $T_{\mathrm{g}}$ between samples synthesized with the $\mathrm{Al}$ and $\mathrm{Fe}$ complexes, the differences in $T_{\mathrm{g}}$ are attributable to disparities in molecular weight. In general, the $\mathrm{Al}$ and $\mathrm{Fe}$ complexes gave similar reactivity, although the Fe complex gave lower molecular weight materials overall.

One of the advantages of epoxide/anhydride copolymerizations is that polymer properties can be tuned not only through the anhydride, but also through the epoxide. Thus, while the polymers produced with PO had $T_{\mathrm{g}}$ values up to $35^{\circ} \mathrm{C}$ higher than that of PLA, we hoped to further increase the $T_{\mathrm{g}}$ by switching to a bulkier, more rigid epoxide. Cyclohexene oxide $(\mathrm{CHO})$ has been shown to give high $T_{\mathrm{g}}$ polycarbonates $\left(\mathrm{T}_{\mathrm{g}} \sim 122^{\circ} \mathrm{C}\right)$ when alternating copolymerized with $\mathrm{CO}_{2},{ }^{27}$ which made it a promising choice. A recent report on the copolymerization of a similar tricyclic anhydride and $\mathrm{CHO}$ found that the resulting polymer had a $T_{\mathrm{g}}$ up to $129{ }^{\circ} \mathrm{C} .{ }^{10}$ Additionally, while $\mathrm{CHO}$ is not currently considered renewable, it could potentially be synthesized from renewable sources through metathesis of plant oils to form 1,4-cyclohexadiene and subsequent epoxidation and hydrogenation. ${ }^{11 \mathrm{f},}{ }^{25}$ We screened all six anhydrides with $\mathrm{CHO}$ (Table 2) and observed a significant increase in $T_{\mathrm{g}}$ compared to the corresponding polymers synthesized with PO (Table 1). We found that reducing the amount of CHO from 1500 to 900 eq and replacing the volume with toluene led to higher molecular weights and narrower $Ð$ values, ${ }^{28}$ with $T_{\mathrm{g}}$ values ranging from 124 to $184^{\circ} \mathrm{C}$. Similar to the PO based polymers, poly(CHO-alt-1a) 
and poly(CHO-alt-1f) had the highest $T_{\mathrm{g}}$ values (Table 2, Entries 1-2 and $11-12$; up to $184{ }^{\circ} \mathrm{C}$ and $165^{\circ} \mathrm{C}$ respectively), which to the best of our knowledge are the highest reported $T_{\mathrm{g}}$ values for aliphatic polyesters synthesized through chain-growth polymerization. 
Table 2. Copolymerization of $\mathbf{1 a}-\mathbf{1} \mathbf{f}$ with cyclohexene oxide (CHO).
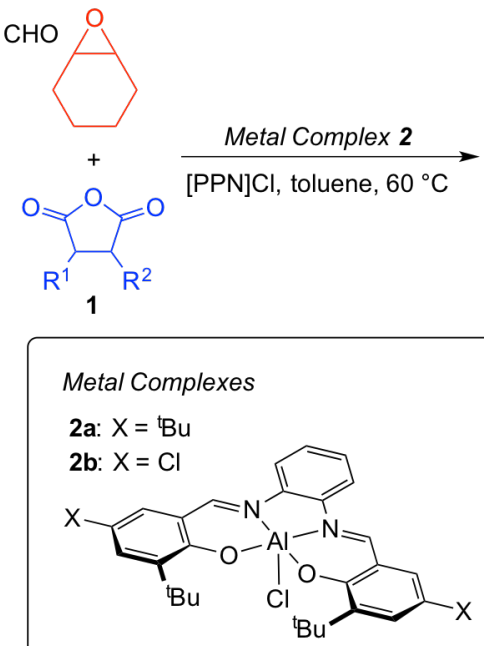

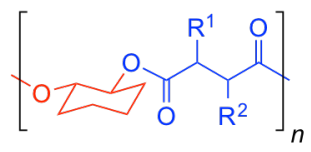

10

11

12

13

14

15

16

17

18

19

20

21

22

23

24

25

26

27

28

29

30

31

32

33

34

35

36

37

38

39

40

41

42

43

44

45

46

47

48

49

50

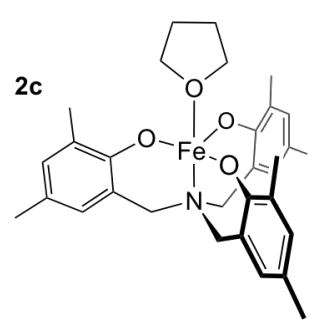

${ }^{f}$ Polymerization run at $70{ }^{\circ} \mathrm{C}$.
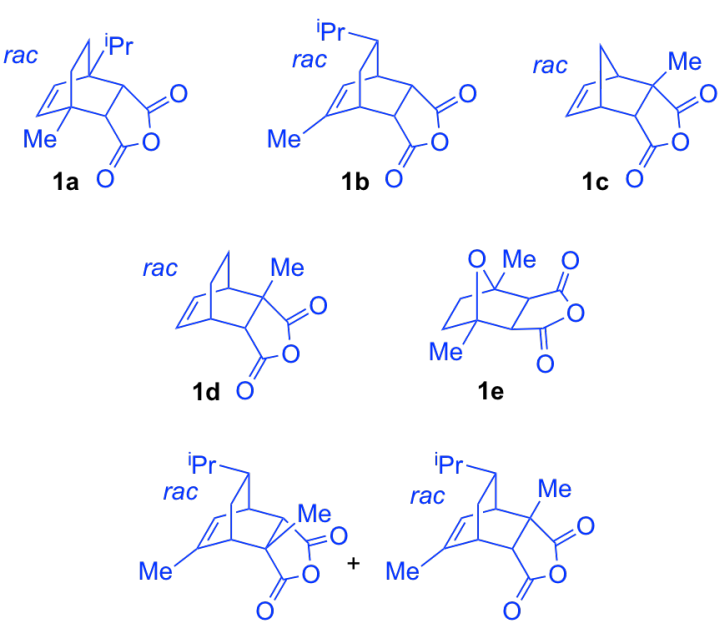

1f: mixture of isomers

\begin{tabular}{|c|c|c|c|c|c|c|c|c|}
\hline Entry & Anhyd. & Complex & $\begin{array}{l}t_{\mathrm{rxn}} \\
\text { (h) }\end{array}$ & $\begin{array}{l}\text { Conv. } \\
(\%)^{b}\end{array}$ & $\begin{array}{c}M_{\mathbf{n}} \\
(\mathbf{k D a})^{c}\end{array}$ & $\bigoplus^{c}$ & $T_{\mathrm{g}}\left({ }^{\circ} \mathbf{C}\right)^{d}$ & $\% \operatorname{cis}^{e}$ \\
\hline $1^{f}$ & $1 a$ & $2 a$ & 60 & 96 & 8.9 & 1.27 & 184 & $>99$ \\
\hline 2 & $1 \mathbf{a}$ & $2 \mathrm{c}$ & 168 & 68 & 4.1 & 1.30 & 162 & $>99$ \\
\hline 3 & $1 b$ & $2 a$ & 24 & $>99$ & 12.2 & 1.40 & 156 & $>99$ \\
\hline 4 & $1 b$ & $2 \mathrm{c}$ & 20 & $>99$ & 11.6 & 1.37 & 151 & $>99$ \\
\hline 5 & $1 \mathrm{c}$ & $2 a$ & 15 & $>99$ & 10.9 & 1.46 & 149 & $>99$ \\
\hline 6 & $1 c$ & $2 c$ & 20 & $>99$ & 8.6 & 1.23 & 149 & $>99$ \\
\hline 7 & 1d & $2 a$ & 10 & $>99$ & 9.4 & 1.40 & 162 & $>99$ \\
\hline 8 & 1d & $2 c$ & 23 & $>99$ & 9.9 & 1.58 & 158 & $>99$ \\
\hline 9 & $1 \mathrm{e}$ & $2 a$ & 48 & $>99$ & 7.3 & 1.46 & 128 & $>99$ \\
\hline 10 & 1e & $2 \mathrm{c}$ & 20 & $>99$ & 9.7 & 1.31 & 124 & $>99$ \\
\hline 11 & 1f & $2 a$ & 25 & $>99$ & 9.5 & 1.24 & 165 & $>99$ \\
\hline 12 & 1f & $2 c$ & 15 & $>99$ & 6.4 & 1.36 & 140 & $>99$ \\
\hline
\end{tabular}

${ }^{a}[\mathrm{CHO}]:[1]:[2]:[(\mathrm{PPN}) \mathrm{Cl}]=900: 300: 1: 0.9^{b}$ Conversion of cyclic anhydride, determined by ${ }^{1} \mathrm{H}$ NMR spectroscopy. ${ }^{c}$ Determined by GPC in THF, at $30{ }^{\circ} \mathrm{C}$, calibrated with polystyrene standards. ${ }^{d}$ Determined by DSC; reported $T_{g}$ values are from the second heat.

${ }^{e}$ Determined by ${ }^{1} \mathrm{H}$ NMR spectroscopy of the mixture of diols obtained from the reductive degradation of the polymer with $\mathrm{LiAlH}_{4}$.

The polymerization rates were significantly lower with $\mathrm{CHO}$, likely due to the increased bulk of the epoxide, and the $\mathrm{Al}$ and $\mathrm{Fe}$ complexes in general had much more comparable rates with CHO than with PO. Complex $\mathbf{2 b}$ was markedly slower than $\mathbf{2 a}$ with $\mathrm{CHO}$, and since no 
epimerization was observed with $\mathbf{2 a}$ (Table 2), likely due to increased steric hindrance, 2a was used for all monomer sets. With 1a, we were unable to reach high conversion using complex $\mathbf{2 a}$ at $60{ }^{\circ} \mathrm{C}$, even at extended reaction times. We subsequently increased the reaction temperature to $70{ }^{\circ} \mathrm{C}$ and were able to achieve $96 \%$ conversion (Table 2, Entry 1 ).

A limitation of the $\mathrm{CHO}$ based polymers is their relatively low molecular weights; poly(CHOalt-1b) synthesized with complex $\mathbf{2 a}$ had the highest molecular weight at a modest $12.2 \mathrm{kDa}$ (Table 2, Entry 3). Analysis by MALDI-TOF-MS for all samples in Table 2 revealed the complete absence of cyclic structures (Figure S26 and S27). In fact, all samples had the expected $\alpha, \omega-\mathrm{Cl}, \mathrm{OH}$ end groups and did not contain any end groups consistent with transesterification such as cyclic structures or $\alpha, \omega-\mathrm{Cl}, \mathrm{Cl}$ end groups. ${ }^{29}$ To our surprise, there was an additional set of signals in the spectra corresponding to polymers without the expected chloride end group. We propose that this could be due to a Meerwein-Ponndorf-Verley-Oppenauer (MPVO) type reaction occurring and generating $\mathrm{CHO}$ based alcohols that can initiate new polymer chains, as previously reported by Duchateau. ${ }^{13 i, 30}$ The resulting increase in the number of initiators would account for the lowered molecular weights compared to the PO based polymers. Additionally, if alcohol was being slowly generated throughout the polymerization, new chains would be generated over the course of the polymerization leading to generally higher $Ð$ values for the CHO polymers (Table $2, \oplus=1.20-1.58) .{ }^{31}$

In conclusion, we have synthesized six tricyclic anhydrides that were either partially (50-63\% by weight) or fully renewably sourced and successfully used them in alternating copolymerizations with propylene oxide, an inexpensive, readily available monomer, and with cyclohexene oxide, which has the potential to be renewably sourced. By varying both the epoxide and the anhydride, we were able to tune the $T_{\mathrm{g}}$ of the resulting polymers over a nearly 
$120{ }^{\circ} \mathrm{C}$ range from $66^{\circ} \mathrm{C}$ to an exceptionally high $184{ }^{\circ} \mathrm{C}$. Polymers synthesized with PO had higher polymerization rates, narrower $\oslash$ values, and higher molecular weights, albeit with generally lower $T_{\mathrm{g}}$ values $\left(66-108^{\circ} \mathrm{C}\right)$. CHO containing polymers had significantly higher $T_{\mathrm{g}}$ values, (124-184 ${ }^{\circ} \mathrm{C}$ ) although they had lower molecular weights, broader $Ð$ values, and substantially decreased polymerization rates. To the best of our knowledge, these are the highest $T_{\mathrm{g}}$ values reported for entirely aliphatic polyesters. The high $T_{\mathrm{g}}$ values of these materials give them potential for use in a variety of higher temperature applications. In addition to exploring other potential renewable monomers, we are currently investigating further catalyst development to allow access to higher molecular weight $\mathrm{CHO}$ based polymers, as well as examining the physical and mechanical properties of these materials.

\title{
ASSOCIATED CONTENT
}

\section{Supporting Information}

Polymerization procedures, synthetic procedures, MALDI-TOF-MS data, GPC traces, DSC traces, TGA analysis of polymers, supplementary experiments, and NMR characterization data. The Supporting Information is available free of charge on the ACS Publications website.

\author{
AUTHOR INFORMATION \\ Corresponding Author \\ * coates@cornell.edu \\ *akleij@iciq.es
}




\author{
Present Addresses \\ $\dagger$ Institute for Complex Molecular Systems and Laboratory of Macromolecular and Organic \\ Chemistry, Eindhoven University of Technology, P.O. Box 513, 5600 MB Eindhoven, The \\ Netherlands
}

\title{
Notes
}

The authors declare no competing financial interest.

\section{ACKNOWLEDGMENT}

Funding for this project was provided by the Center for Sustainable Polymers, an NSF Center for Chemical Innovation (CHE-1413862). N.J.V.Z. acknowledges the NSF for financial support through the IGERT program (DGE-0903653). L.P.C. and A.W.K. acknowledge the Spanish Ministerio de Economía y Competitividad (MINECO) for financial support through project CTQ-2014-60419-R and for FPI and EEBB fellowships. Severo Ochoa Excellence Accreditation 2014-2018 is acknowledged for financial support through project SEV-2013-0319. Dr. Noemí Cabello is acknowledged for the MALDI-TOF analyses. This work made use of the Cornell Center for Materials Research Shared Facilities, which are supported through the NSF MRSEC program (DMR-1120296). We thank Kyle O’Connor for helpful discussions.

\section{REFERENCES}

(1) (a) Gandini, A. The irruption of polymers from renewable resources on the scene of macromolecular science and technology. Green Chem. 2011, 13, 1061-1083. (b) Ragauskas, A. J.; Williams, C. K.; Davison, B. H.; Britovsek, G.; Cairney, J.; Eckert, C. A.; Frederick, W. J.; Hallett, J. P.; Leak, D. J.; Liotta, C. L.; Mielenz, J. R.; Murphy, R.; Templer, R.; Tschaplinski, T. 
The Path Forward for Biofuels and Biomaterials. Science 2006, 311, 484-489. (c) Mecking, S. Nature or Petrochemistry?-Biologically Degradable Materials. Angew. Chem., Int. Ed. 2004, 43, 1078-1085. (d) Gross, R. A.; Kalra, B. Biodegradable Polymers for the Environment. Science 2002, 297, 803-807.

(2) (a) Hillmyer, M. A.; Tolman, W. B. Aliphatic Polyester Block Polymers: Renewable, Degradable, and Sustainable. Acc. Chem. Res. 2014, 47, 2390-2396. (b) Vert, M. Aliphatic Polyesters: Great Degradable Polymers That Cannot Do Everything. Biomacromolecules 2005, 6, 538-546. (c) Amass, W.; Amass, A.; Tighe, B. A review of biodegradable polymers: uses, current developments in the synthesis and characterization of biodegradable polyesters, blends of biodegradable polymers and recent advances in biodegradation studies. Polym. Int 1998, 47, 89144.

(3) (a) Olson, D. A.; Gratton, S. E. A.; DeSimone, J. M.; Sheares, V. V. Amorphous Linear Aliphatic Polyesters for the Facile Preparation of Tunable Rapidly Degrading Elastomeric Devices and Delivery Vectors. J. Am. Chem. Soc. 2006, 128, 13625-13633. (b) Müller, R.-J.; Kleeberg, I.; Deckwer, W.-D. Biodegradation of polyesters containing aromatic constituents. J. Biotechnol. 2001, 86, 87-95. (c) Brown, A. H.; Sheares, V. V. Amorphous Unsaturated Aliphatic Polyesters Derived from Dicarboxylic Monomers Synthesized by Diels-Alder Chemistry. Macromolecules 2007, 40, 4848-4853.

(4) Lecomte, P.; Jérôme, C. In Synthetic Biodegradable Polymers; Rieger, B., Künkel, A., Coates, W. G., Reichardt, R., Dinjus, E., Zevaco, A. T., Eds.; Springer Berlin Heidelberg: Berlin, Heidelberg, 2012, p 173-217. 
(5) (a) Engels, H.-W.; Pirkl, H.-G.; Albers, R.; Albach, R. W.; Krause, J.; Hoffmann, A.; Casselmann, H.; Dormish, J. Polyurethanes: Versatile Materials and Sustainable Problem Solvers for Today's Challenges. Angew. Chem., Int. Ed. 2013, 52, 9422-9441. (b) Gupta, A. P.; Kumar, V. New emerging trends in synthetic biodegradable polymers - Polylactide: A critique. Eur. Polym. J. 2007, 43, 4053-4074. (c) Datta, R.; Henry, M. Lactic acid: recent advances in products, processes and technologies - a review. J. Chem. Technol. Biotechnol. 2006, 81, 1119-1129. (d) Auras, R.; Harte, B.; Selke, S. An Overview of Polylactides as Packaging Materials. Macromol. Biosci. 2004, 4, 835-864. (e) Vink, E. T. H.; Rábago, K. R.; Glassner, D. A.; Gruber, P. R. Applications of life cycle assessment to NatureWorks ${ }^{\mathrm{TM}}$ polylactide (PLA) production. Polym. Degrad. Stab. 2003, 80, 403-419. (f) Ikada, Y.; Tsuji, H. Biodegradable polyesters for medical and ecological applications. Macromol. Rapid Commun. 2000, 21, 117132.

(6) Paul, S.; Zhu, Y.; Romain, C.; Brooks, R.; Saini, P. K.; Williams, C. K. Ring-opening copolymerization (ROCOP): synthesis and properties of polyesters and polycarbonates. Chem. Commun. 2015, 51, 6459-6479.

(7) (a) Fenouillot, F.; Rousseau, A.; Colomines, G.; Saint-Loup, R.; Pascault, J. P. Polymers from renewable 1,4:3,6-dianhydrohexitols (isosorbide, isomannide and isoidide): A review. Prog. Polym. Sci. 2010, 35, 578-622. (b) Storbeck, R.; Ballauff, M. Synthesis and properties of polyesters based on 2,5-furandicarboxylic acid and 1,4:3,6-dianhydrohexitols. Polymer 1993, 34, $5003-5006$.

(8) Fiore, G. L.; Jing, F.; Young, J. V. G.; Cramer, C. J.; Hillmyer, M. A. High T $T_{\text {gliphatic }}$ polyesters by the polymerization of spirolactide derivatives. Polym. Chem. 2010, 1, 870-877. 
(9) Lavilla, C.; Alla, A.; Martínez de Ilarduya, A.; Muñoz-Guerra, S. High $T_{\mathrm{g}}$ Bio-Based Aliphatic Polyesters from Bicyclic d-Mannitol. Biomacromolecules 2013, 14, 781-793.

(10) Han, B.; Zhang, L.; Liu, B.; Dong, X.; Kim, I.; Duan, Z.; Theato, P. Controllable Synthesis of Stereoregular Polyesters by Organocatalytic Alternating Copolymerizations of Cyclohexene Oxide and Norbornene Anhydrides. Macromolecules 2015, 48, 3431-3437.

(11) (a) Zhu, L.; Liu, D.; Wu, L.; Feng, W.; Zhang, X.; Wu, J.; Fan, D.; Lü, X.; Lu, R.; Shi, Q. A trinuclear $\left[\mathrm{Zn}_{3}(\mathrm{~L})_{2}(\mathrm{OAc})_{2}\right]$ complex based on the asymmetrical bis-Schiff-base ligand $\mathrm{H}_{2} \mathrm{~L}$ for ring-opening copolymerization of $\mathrm{CHO}$ and MA. Inorg. Chem. Commun. 2013, 37, 182-185. (b) Liu, D.-F.; Wu, L.-Y.; Feng, W.-X.; Zhang, X.-M.; Wu, J.; Zhu, L.-Q.; Fan, D.-D.; Lü, X.-Q.; Shi, Q. Ring-opening copolymerization of $\mathrm{CHO}$ and $\mathrm{MA}$ catalyzed by mononuclear $\left[\mathrm{Zn}\left(\mathrm{L}_{2}\right)\left(\mathrm{H}_{2} \mathrm{O}\right)\right]$ or trinuclear $\left[\mathrm{Zn}_{3}\left(\mathrm{~L}_{2}\right)_{2}(\mathrm{OAc})_{2}\right]$ complex based on the asymmetrical bis-Schiff-base ligand precursor. J. Mol. Catal. A: Chem. 2014, 382, 136-145. (c) Liu, Y.; Xiao, M.; Wang, S.; Xia, L.; Hang, D.; Cui, G.; Meng, Y. Mechanism studies of terpolymerization of phthalic anhydride, propylene epoxide, and carbon dioxide catalyzed by ZnGA. RSC Advances 2014, 4, 9503-9508. (d) Saini, P. K.; Romain, C.; Zhu, Y.; Williams, C. K. Di-magnesium and zinc catalysts for the copolymerization of phthalic anhydride and cyclohexene oxide. Polym. Chem. 2014, 5, 6068-6075. (e) Wu, L.-y.; Fan, D.-d.; Lü, X.-q.; Lu, R. Ring-opening copolymerization of cyclohexene oxide and maleic anhydride catalyzed by mononuclear $\left[\mathrm{Zn}(\mathrm{L})\left(\mathrm{H}_{2} \mathrm{O}\right)\right]$ or binuclear $\left[\mathrm{Zn}_{2}(\mathrm{~L})(\mathrm{OAc})_{2}\left(\mathrm{H}_{2} \mathrm{O}\right)\right]$ complex based on the Salen-type Schiff-base ligand. Chin. J. Polym. Sci. 2014, 32, 768-777. (f) Winkler, M.; Romain, C.; Meier, M. A. R.; Williams, C. K. Renewable polycarbonates and polyesters from 1,4-cyclohexadiene. Green Chem. 2015, 17, 300-306. (g) Zhu, Y.; Romain, C.; Williams, C. K. Selective Polymerization Catalysis: Controlling the Metal 
Chain End Group to Prepare Block Copolyesters. J. Am. Chem. Soc. 2015, 137, 12179-12182.

(h) Thevenon, A.; Garden, J. A.; White, A. J. P.; Williams, C. K. Dinuclear Zinc Salen Catalysts for the Ring Opening Copolymerization of Epoxides and Carbon Dioxide or Anhydrides. Inorg. Chem. 2015, 54, 11906-11915. (i) Garden, J. A.; Saini, P. K.; Williams, C. K. Greater than the Sum of Its Parts: A Heterodinuclear Polymerization Catalyst. J. Am. Chem. Soc. 2015, 137, $15078-15081$.

(12) Takasu, A.; Ito, M.; Inai, Y.; Hirabayashi, T.; Nishimura, Y. Syntheis of Biodegradable Polyesters by Ring-Opening Copolymerization of Cyclic Anhydrides Containing a Double Bond with 1,2-Epoxybutane and One-Pot Preparation of the Itaconic Acid-Based Polymeric Network. Polym. J. 1999, 31, 961-969.

(13) (a) Huijser, S.; HosseiniNejad, E.; Sablong, R.; de Jong, C.; Koning, C. E.; Duchateau, R. Ring-Opening Co- and Terpolymerization of an Alicyclic Oxirane with Carboxylic Acid Anhydrides and $\mathrm{CO}_{2}$ in the Presence of Chromium Porphyrinato and Salen Catalysts. Macromolecules 2011, 44, 1132-1139. (b) Robert, C.; de Montigny, F.; Thomas, C. M. Tandem synthesis of alternating polyesters from renewable resources. Nat. Commun. 2011, 2, 586. (c) Darensbourg, D. J.; Poland, R. R.; Escobedo, C. Kinetic Studies of the Alternating Copolymerization of Cyclic Acid Anhydrides and Epoxides, and the Terpolymerization of Cyclic Acid Anhydrides, Epoxides, and $\mathrm{CO}_{2}$ Catalyzed by (salen) $\mathrm{Cr}^{\mathrm{III}} \mathrm{Cl}$. Macromolecules 2012, 45, 2242-2248. (d) Hosseini Nejad, E.; Paoniasari, A.; Koning, C. E.; Duchateau, R. Semi-aromatic polyesters by alternating ring-opening copolymerisation of styrene oxide and anhydrides. Polym. Chem. 2012, 3, 1308-1313. (e) Hosseini Nejad, E.; van Melis, C. G. W.; Vermeer, T. J.; Koning, C. E.; Duchateau, R. Alternating Ring-Opening Polymerization of Cyclohexene Oxide and 
Anhydrides: Effect of Catalyst, Cocatalyst, and Anhydride Structure. Macromolecules 2012, 45, 1770-1776. (f) Bernard, A.; Chatterjee, C.; Chisholm, M. H. The influence of the metal (Al, Cr and $\mathrm{Co}$ ) and the substituents of the porphyrin in controlling the reactions involved in the copolymerization of propylene oxide and cyclic anhydrides by porphyrin metal(III) complexes. Polymer 2013, 54, 2639-2646. (g) Harrold, N. D.; Li, Y.; Chisholm, M. H. Studies of RingOpening Reactions of Styrene Oxide by Chromium Tetraphenylporphyrin Initiators. Mechanistic and Stereochemical Considerations. Macromolecules 2013, 46, 692-698. (h) Liu, J.; Bao, Y.-Y.; Liu, Y.; Ren, W.-M.; Lu, X.-B. Binuclear chromium-salan complex catalyzed alternating copolymerization of epoxides and cyclic anhydrides. Polym. Chem. 2013, 4, 1439-1444. (i) Nejad, E. H.; Paoniasari, A.; van Melis, C. G. W.; Koning, C. E.; Duchateau, R. Catalytic RingOpening Copolymerization of Limonene Oxide and Phthalic Anhydride: Toward Partially Renewable Polyesters. Macromolecules 2013, 46, 631-637. (j) Biermann, U.; Sehlinger, A.; Meier, M. A. R.; Metzger, J. O. Catalytic copolymerization of methyl 9,10-epoxystearate and cyclic anhydrides under neat conditions. Eur. J. Lipid Sci. Technol. 2016, 118, 104-110. (k) DiCiccio, A. M.; Coates, G. W. Ring-Opening Copolymerization of Maleic Anhydride with Epoxides: A Chain-Growth Approach to Unsaturated Polyesters. J. Am. Chem. Soc. 2011, 133, $10724-10727$.

(14) Longo, J. M.; DiCiccio, A. M.; Coates, G. W. Poly(propylene succinate): A New Polymer Stereocomplex. J. Am. Chem. Soc. 2014, 136, 15897-15900.

(15) (a) Robert, C.; Ohkawara, T.; Nozaki, K. Manganese-Corrole Complexes as Versatile Catalysts for the Ring-Opening Homo- and Co-Polymerization of Epoxide. Chem. - Eur. J. 2014, 20, 4789-4795. (b) Liu, D.-F.; Zhu, L.-Q.; Wu, J.; Wu, L.-Y.; Lu, X.-Q. Ring-opening 
copolymerization of epoxides and anhydrides using manganese(iii) asymmetrical Schiff base complexes as catalysts. RSC Advances 2015, 5, 3854-3859. (c) Liu, D.; Zhang, Z.; Zhang, X.; Lü, X. Alternating Ring-Opening Copolymerization of Cyclohexene Oxide and Maleic Anhydride with Diallyl-Modified Manganese(iii)-Salen Catalysts. Aust. J. Chem. 2016, 69, 4755.

(16) (a) Aida, T.; Inoue, S. Catalytic reaction on both sides of a metalloporphyrin plane. Alternating copolymerization of phthalic anhydride and epoxypropane with an aluminum porphyrin-quaternary salt system. J. Am. Chem. Soc. 1985, 107, 1358-1364. (b) Aida, T.; Sanuki, K.; Inoue, S. Well-controlled polymerization by metalloporphyrin. Synthesis of copolymer with alternating sequence and regulated molecular weight from cyclic acid anhydride and epoxide catalyzed by the system of aluminum porphyrin coupled with quaternary organic salt. Macromolecules 1985, 18, 1049-1055. (c) Van Zee, N. J.; Coates, G. W. Alternating Copolymerization of Propylene Oxide with Biorenewable Terpene-Based Cyclic Anhydrides: A Sustainable Route to Aliphatic Polyesters with High Glass Transition Temperatures. Angew. Chem., Int. Ed. 2015, 54, 2665-2668. (d) Van Zee, N. J.; Sanford, M. J.; Coates, G. W. Electronic Effects of Aluminum Complexes in the Copolymerization of Propylene Oxide with Tricyclic Anhydrides: Access to Well-Defined, Functionalizable Aliphatic Polyesters. J. Am. Chem. Soc. 2016, 138, 2755-2761.

(17) Whiteoak, C. J.; Gjoka, B.; Martin, E.; Belmonte, M. M.; Escudero-Adán, E. C.; Zonta, C.; Licini, G.; Kleij, A. W. Reactivity Control in Iron(III) Amino Triphenolate Complexes: Comparison of Monomeric and Dimeric Complexes. Inorg. Chem. 2012, 51, 10639-10649. 
(18) Taherimehr, M.; Al-Amsyar, S. M.; Whiteoak, C. J.; Kleij, A. W.; Pescarmona, P. P. High activity and switchable selectivity in the synthesis of cyclic and polymeric cyclohexene carbonates with iron amino triphenolate catalysts. Green Chem. 2013, 15, 3083-3090.

(19) Mundil, R.; Hošt'álek, Z.; Šeděnková, I.; Merna, J. Alternating ring-opening copolymerization of cyclohexene oxide with phthalic anhydride catalyzed by iron(III) salen complexes. Macromol. Res. 2015, 23, 161-166.

(20) (a) Swift, K. A. D. Catalytic Transformations of the Major Terpene Feedstocks. Top. Catal. 2004, 27, 143-155. (b) Behr, A.; Johnen, L. Myrcene as a Natural Base Chemical in Sustainable Chemistry: A Critical Review. ChemSusChem 2009, 2, 1072-1095. (c) Wilbon, P. A.; Chu, F.; Tang, C. Progress in Renewable Polymers from Natural Terpenes, Terpenoids, and Rosin. Macromol. Rapid Commun. 2013, 34, 8-37. (d) Dakshinamoorthy, D.; Weinstock, A. K.; Damodaran, K.; Iwig, D. F.; Mathers, R. T. Diglycerol-Based Polyesters: Melt Polymerization with Hydrophobic Anhydrides. ChemSusChem 2014, 7, 2923-2929. (e) Zhao, J. P.; Schlaad, H. Synthesis of Terpene-Based Polymers. Adv. Poly. Sci. 2013, 253, 151-190.

(21) (a) Roman-Leshkov, Y.; Barrett, C. J.; Liu, Z. Y.; Dumesic, J. A. Production of dimethylfuran for liquid fuels from biomass-derived carbohydrates. Nature 2007, 447, 982-985. (b) Rasmussen, H.; Sørensen, H. R.; Meyer, A. S. Formation of degradation compounds from lignocellulosic biomass in the biorefinery: sugar reaction mechanisms. Carbohydr. Res. 2014, 385, 45-57. (c) Chen, M.-Y.; Chen, C.-B.; Zada, B.; Fu, Y. Perovskite type oxide-supported Ni catalysts for the production of 2,5-dimethylfuran from biomass-derived 5hydroxymethylfurfural. Green Chem. 2016, 18, 3858-3866. 
(22) The Merck Index; $14^{\text {th }}$ ed.; Merck \& Co., Inc.: Whitehouse Station, NJ, 2006.

(23) Hajian, H.; Yusoff, W. M. W. Itaconic Acid Production by Microorganisms: A Review. Curr. Res. J. Biol. Sci. 2015, 7, 37-42.

(24) Top Value Added Chemicals from Biomass, U.S. Department of Energy, 2004. http://www.nrel.gov/docs/fy04osti/35523.pdf (accessed July 3, 2016).

(25) Mathers, R. T.; Shreve, M. J.; Meyler, E.; Damodaran, K.; Iwig, D. F.; Kelley, D. J. Synthesis and Polymerization of Renewable 1,3-Cyclohexadiene Using Metathesis, Isomerization, and Cascade Reactions with Late-metal Catalysts. Macromol. Rapid Commun. 2011, 32, 1338-1342.

(26) Further discussion on the effects of adventitious water and the resulting diacid, a proposed initiation mechanism (Scheme S1) and representative GPC traces (Figure S25) are in the SI.

(27) (a) Coates, G. W.; Moore, D. R. Discrete Metal-based Catalysts for the Copolymerization of $\mathrm{CO}_{2}$ and Epoxides: Discovery, Reactivity, Optimization, and Mechanism. Angew. Chem. Int. Ed. 2004, 43, 6618-6639. (b) Kember, M. R.; Buchard, A.; Williams, C. K. Catalysts for $\mathrm{CO}_{2}$ /epoxide copolymerisation. Chem. Commun. 2011, 47, 141-163.

(28) For a comparison of polymerizations with and without toluene see Table S1.

(29) MALDI-TOF-MS analysis is shown in the Supporting Information (Figures S26-28).

(30) van Meerendonk, W. J.; Duchateau, R.; Koning, C. E.; Gruter, G.-J. M. Unexpected Side Reactions and Chain Transfer for Zinc-Catalyzed Copolymerization of Cyclohexene Oxide and Carbon Dioxide. Macromolecules 2005, 38, 7306-731. 
(31) Another possible cause of this cyclohexenol end group, decreased $M_{\mathrm{n}}$ values, and increased $Ð$ values is elimination of $\mathrm{Cl}^{-}$from $\alpha, \omega-\mathrm{Cl}, \mathrm{OH}$ terminated polymers. However, as further discussed in the SI, while we have not been able to definitively rule out the possibility of elimination, we believe that the MPVO reaction is more likely. 
Maria J. Sanford, ${ }^{\ddagger}$ Leticia Peña Carrodeguas, ${ }^{\S}$ Nathan J. Van Zee, ${ }^{\dagger, *}$ Arjan W. Kleij, ${ }^{*, \S}$ and Geoffrey W. Coates ${ }^{*, *}$

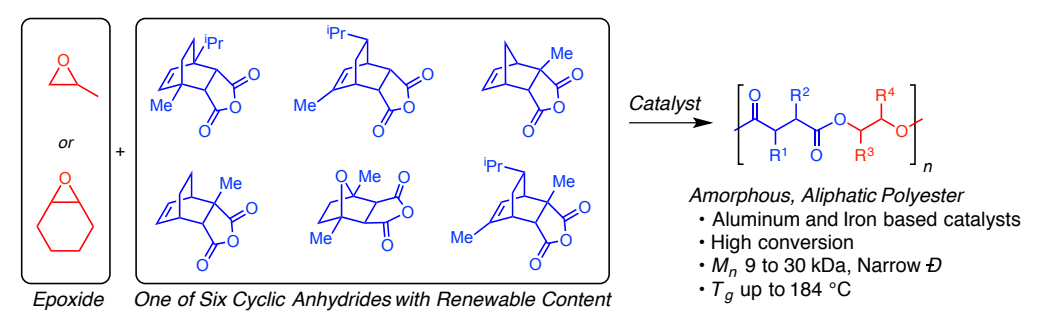




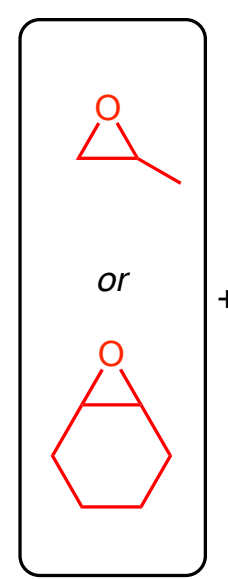

Epoxide

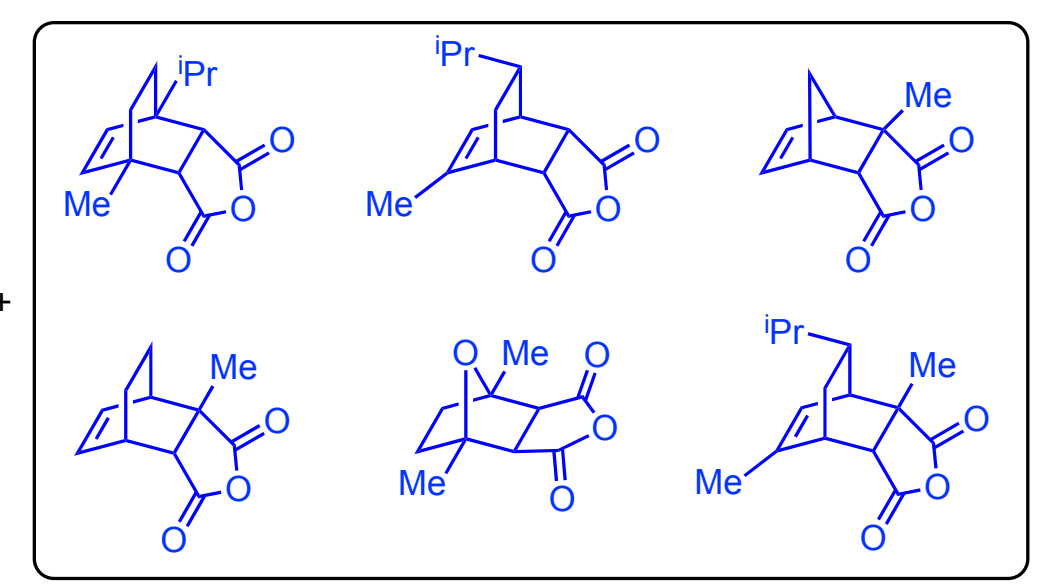

One of Six Cyclic Anhydrides with Renewable Content

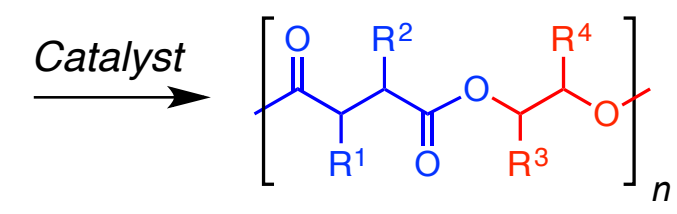

Amorphous, Aliphatic Polyester

- Aluminum and Iron based catalysts

- High conversion

- $M_{n} 9$ to $30 \mathrm{kDa}$, Narrow $\bigoplus$

- $T_{g}$ up to $184^{\circ} \mathrm{C}$ 

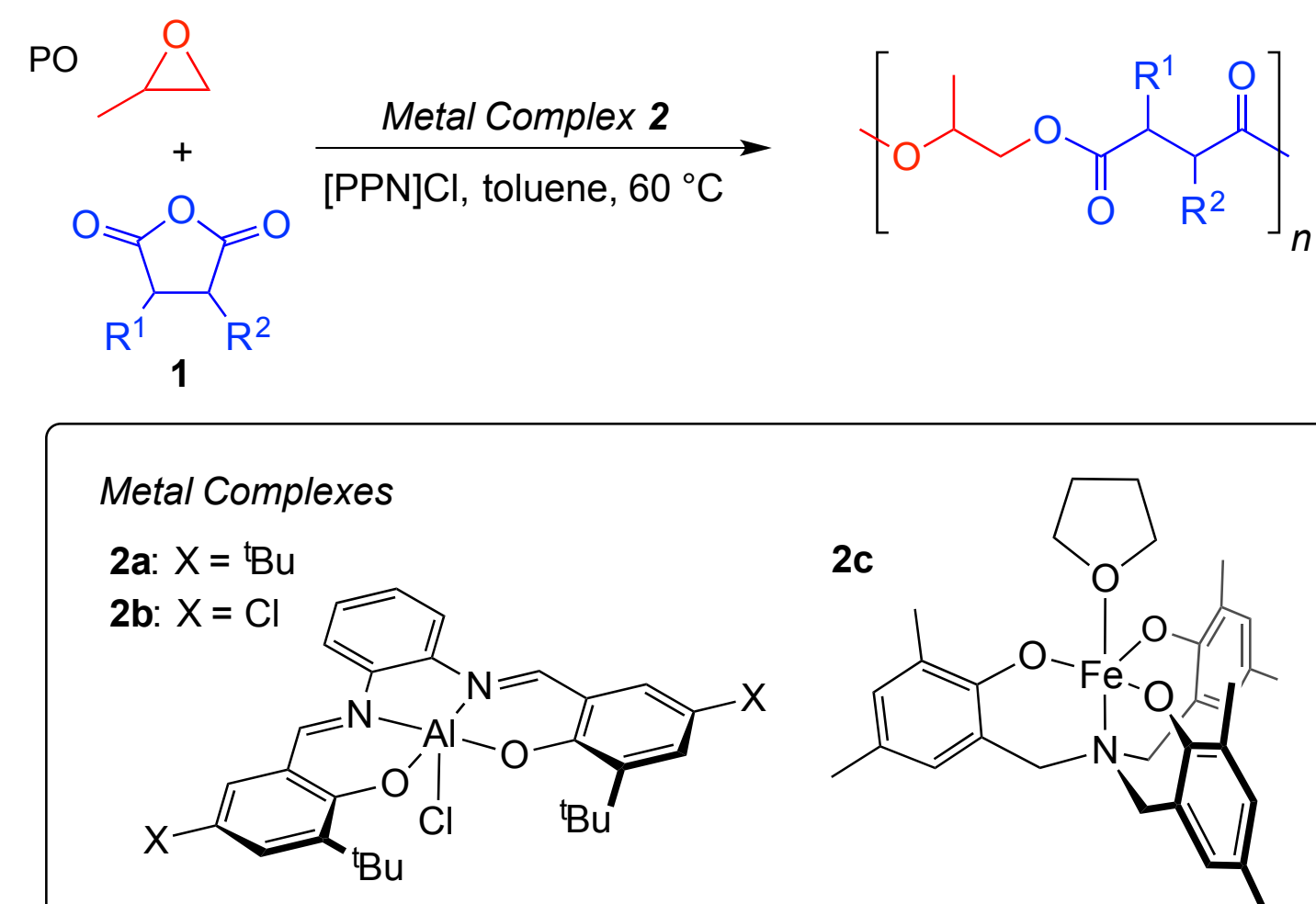

2c
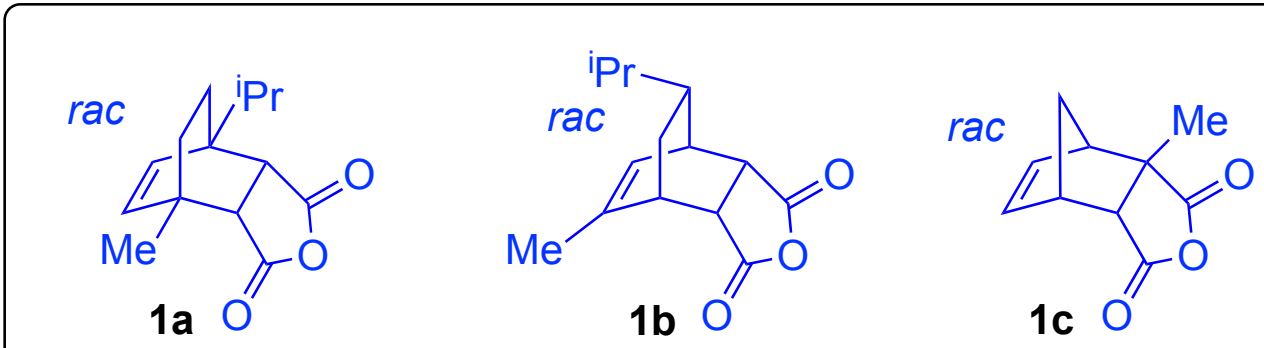

rac
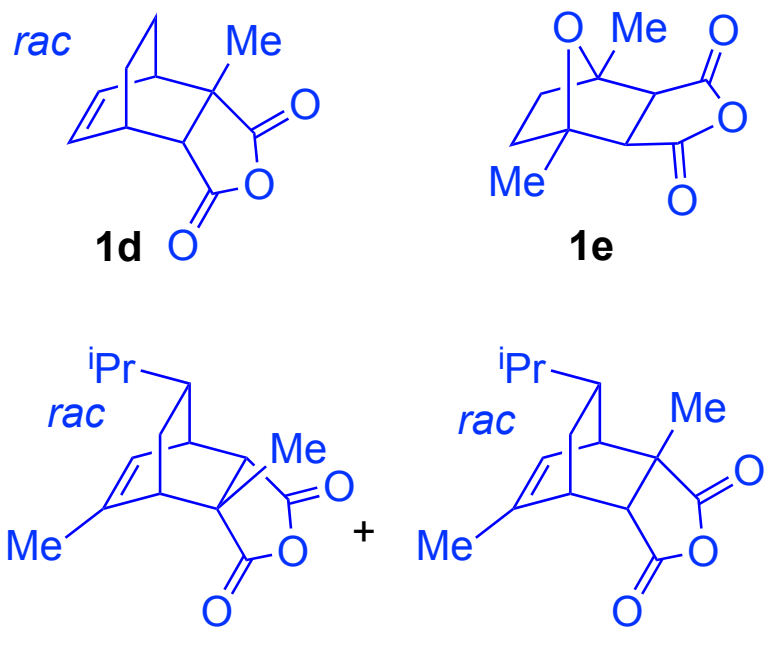

1f: mixture of isomers 

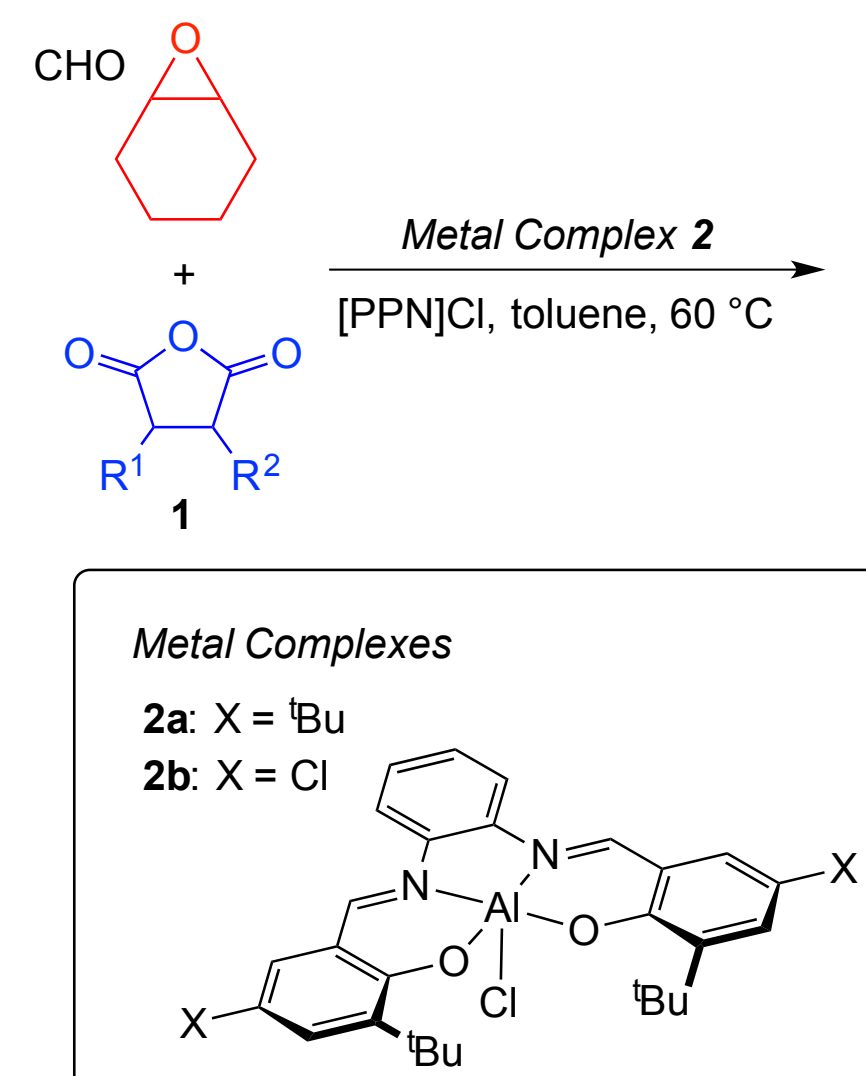

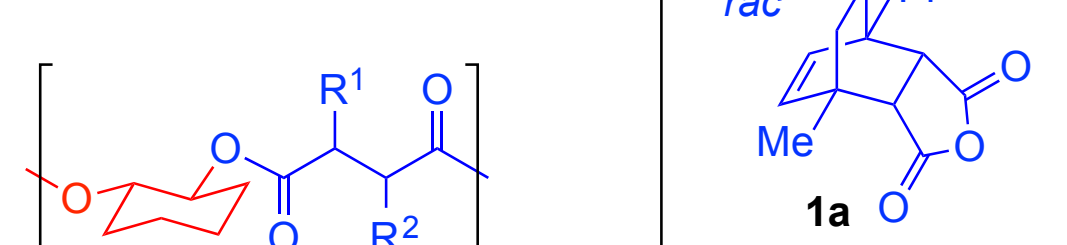

1a

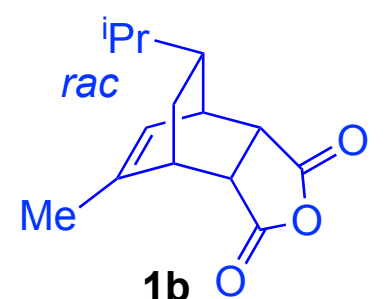

1b

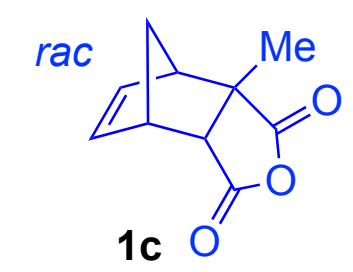

$1 c$ 2c

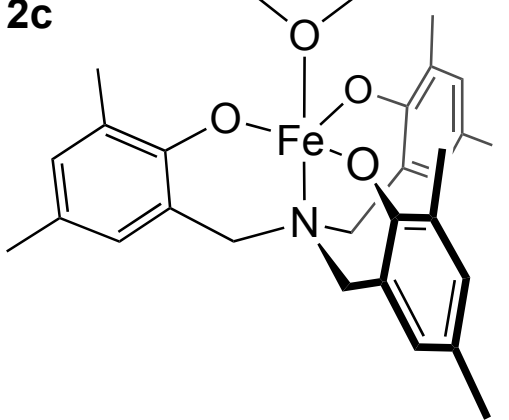

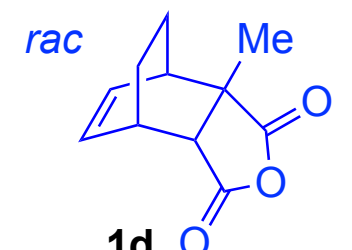

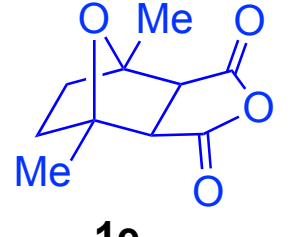

$1 \mathrm{e}$

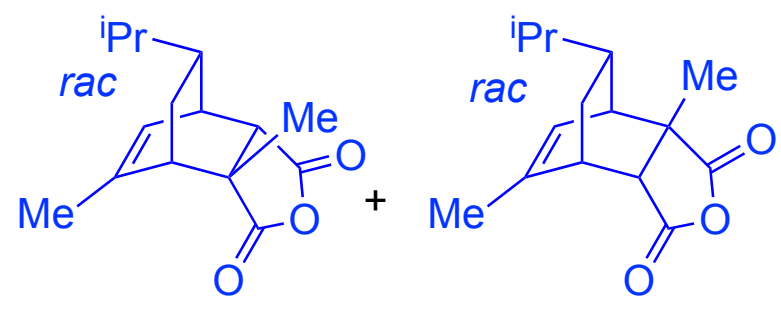

1f: mixture of isomers 


1
2
3
4
5
6
7
8
9
10
11
12
13
14
15
16
17
18
19
20
21
22
23
24
25
26
27
28
29
30
31
32
33
34
35
36
37
38
39
40
41
42
43
40
45
49
50
51
52
53
55
50

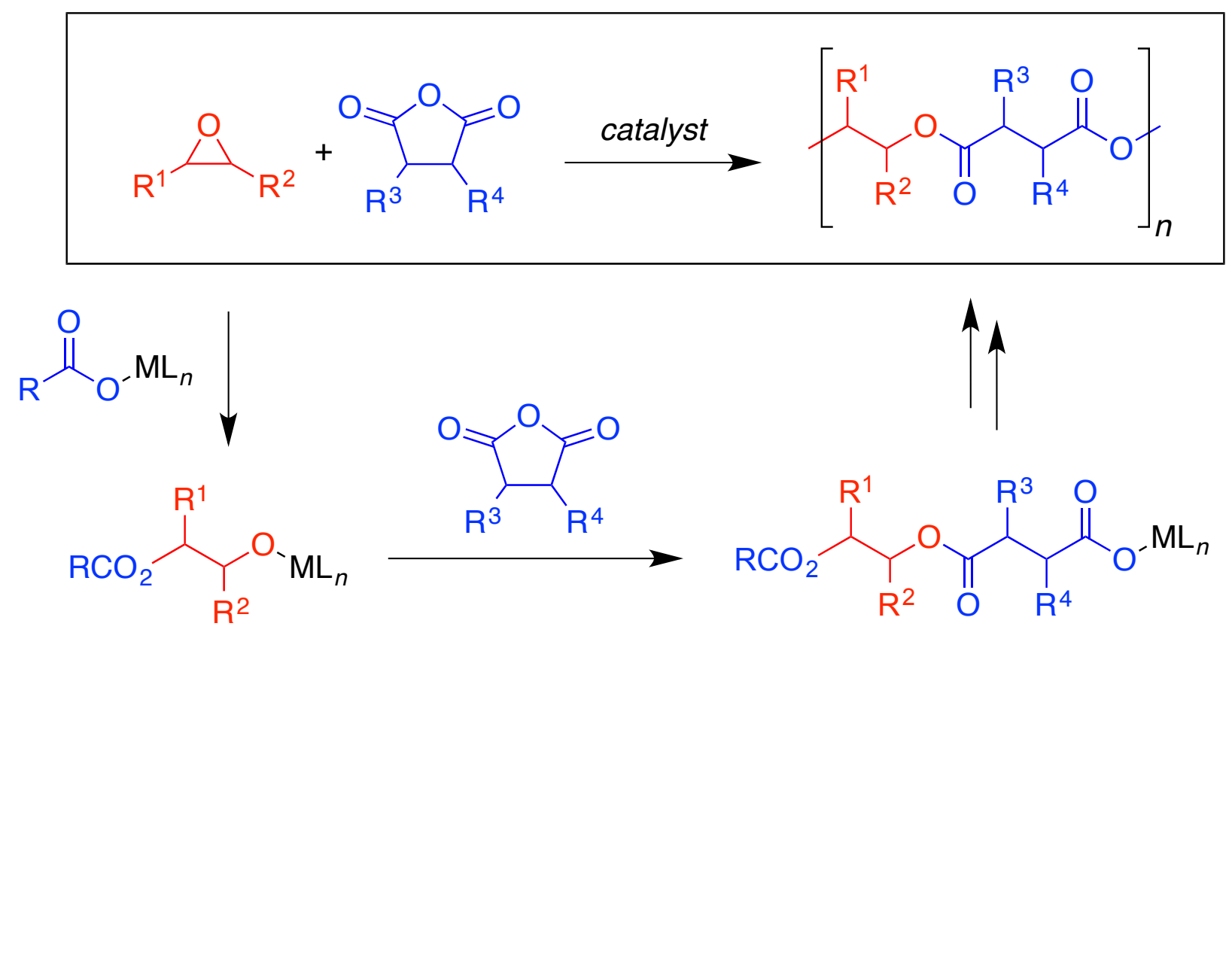

ACS Paragon Plus Environment 
Terpenes: Naturally occurring feedstocks<smiles>C=C(C)CCOP(=O)([O-])OP([O-])([O-])(O)O</smiles>

isopentenyl pyrophosphate<smiles>CC(C)=CCOP(=O)([O-])OP(=O)([O-])O</smiles>

dimethylallyl pyrophosphate

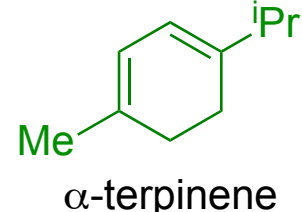

Biosynthesis

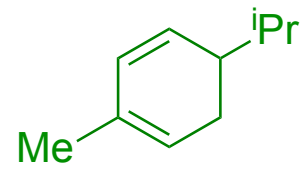

$\alpha$-phellandrene

2,5-Dimethylfuran: Derived from abundant carbohydrates

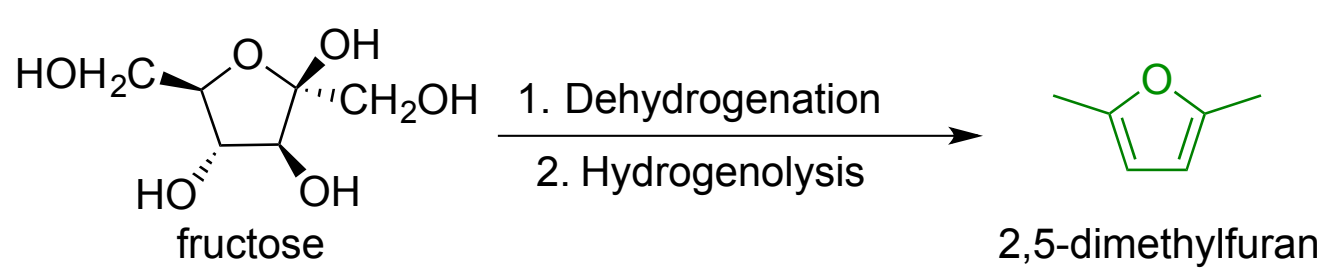

Citraconic Anhydride: Produced from biosourced itaconic acid

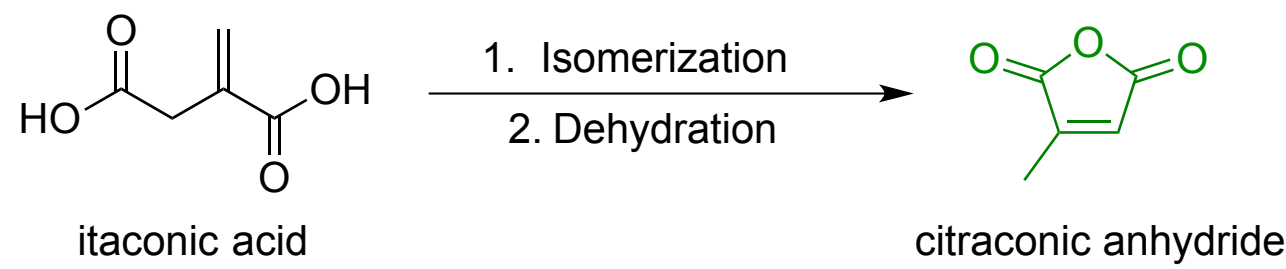


a) Terpene based monomers<smiles>CC1=CC=C(C(C)C)CC1</smiles>

$\alpha$-terpinene<smiles>CC1=CCC(C(C)C)C=C1</smiles>

$\alpha$-phellandrene

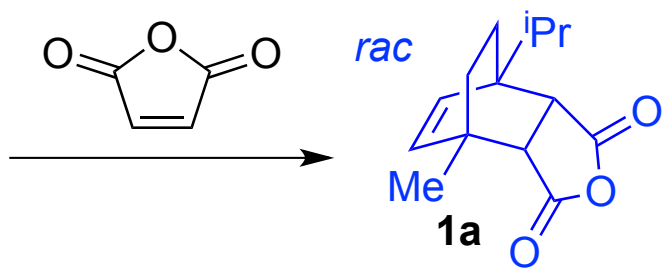

$58 w t \%$ renewable<smiles>CC1=CC2C3C(=O)OC(=O)C3C(C1C)C2C(C)C</smiles>

monomers

b) Citraconic anhydride based monomers

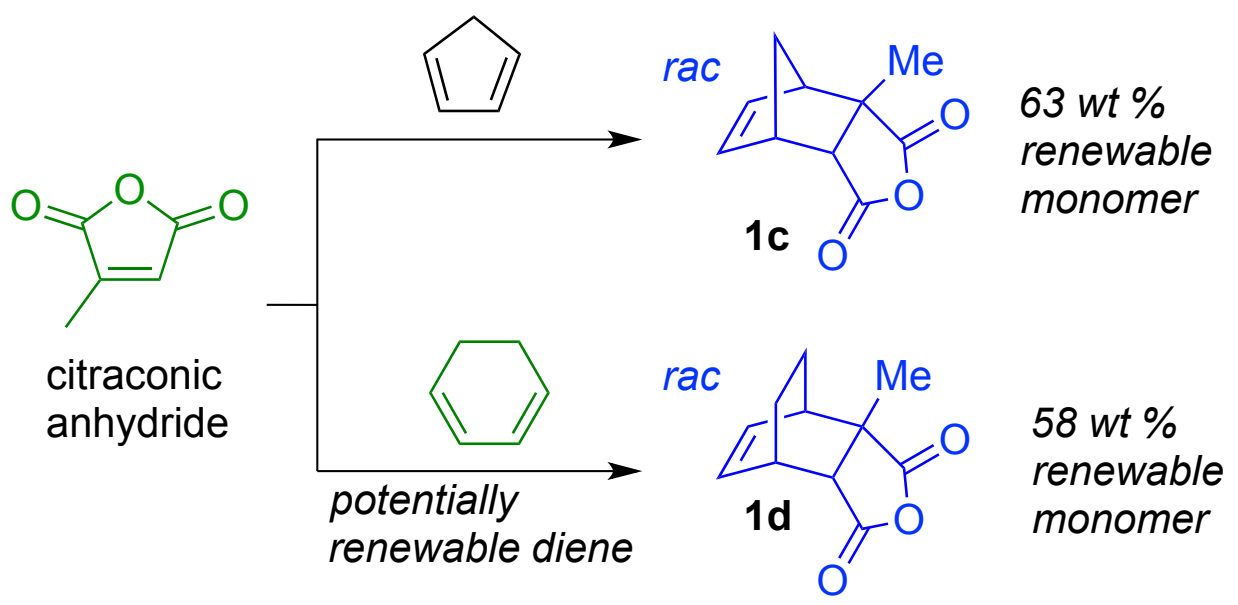

c) 2,5-Dimethylfuran based monomer

2,5-dimethylfuran<smiles>O=C1C=CC(=O)O1</smiles><smiles>CCOC(=O)C1C2(C)CCC(O2)C1(C)C</smiles>

50 wt \% renewable monomer

d) Citraconic anhydride and $\alpha$-phellandrene based monomers<smiles>CC1=CC(=O)OC1=O</smiles><smiles>CC1=CCC(C(C)C)C=C1</smiles>

$\alpha$-phellandrene<smiles>CC1=CC23C(=O)OC(=O)C1C(C(C)C)C2C=C3C</smiles>

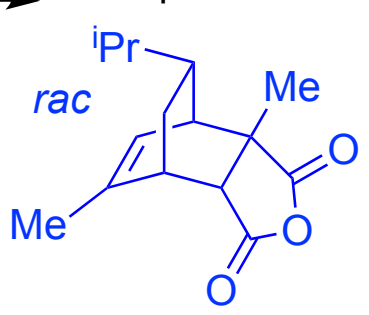

1f: mixture of isomers 